\title{
A SUSTENTABILIDADE URBANA E A LEGISLAÇÃO PARA REGULARIZAÇÃO FUNDIÁRIA NO BRASIL
}

\author{
Urban sustainability and legislation for Land Regulation in Brazil
}

\author{
Andressa Schäfer ${ }^{1}$; Simone Gasperin de Albuquerque ${ }^{2}$
}

${ }^{1}$ Bacharel em Direito pela Universidade Regional Integrada do Alto Uruguai e das Missões. E-mail: andressa.schafer19@hotmail.com

${ }^{2}$ Professora do Curso de Direito da Universidade Regional Integrada do Alto Uruguai e das Missões (URI Erechim/RS).E-mail: salbuquerque@uri.com.br

Data do recebimento: 01/03/2021 - Data do aceite: 26/05/2021

RESUMO: O artigo apresenta um estudo sobre a Sustentabilidade Urbana como um meio da Regularização Fundiária. Inicialmente busca-se conceituar e definir a Regularização Fundiária no Ordenamento Jurídico Brasileiro. A problemática discorre sobre a possibilidade ou não do uso da legislação contemporânea sobre Regularização Fundiária ser um mecanismo para implementar a sustentabilidade urbana. A pesquisa analisa a Lei $n^{\circ} .13 .465 / 2017$ e os seus requisitos. Examinam-se os institutos Jurídicos que podem e devem ser utilizados na Regularização Fundiária Urbana, segundo os dispositivos legais. Reflete-se ainda, a efetividade da Regularização Fundiária Urbana no que concerne ao direito à moradia. Observa-se que, para a efetividade do instituto em tela, é preciso que se trabalhe a Regularização Fundiária Urbana em conjunto com outros institutos. Conclui-se pela necessidade de integração da regularização fundiária para a manutenção de um meio ambiente sustentável, já que imprescindíveis para o futuro das próximas gerações. Este trabalho utiliza o método indutivo e o procedimento de pesquisa bibliográfico e documental.

Palavras-chave: Regularização Fundiária. Sustentabilidade. Meio Ambiente.

ABSTRACT: The article presents a study on Urban Sustainability as a means of Land Regularization. Initially, it seeks to conceptualize and define Land Regularization within the Brazilian Legal System. The problem discusses whether or not the use of contemporary legislation on Land Regularization is 
a mechanism to implement urban sustainability. The research analyzes Law $\mathrm{n}^{\mathrm{o}} .13,465 / 2017$ and its requirements. It examines the Legal institutes that can and should be used in Urban Land Regularization, according to legal provisions. The effectiveness of Urban Land Regularization with regard to the right to housing is also concerned. It is observed that, for the effectiveness of the institute in question, it is necessary to work the Urban Land Regularization together with other institutes. The need to integrate land regularization to maintain a sustainable environment is described, as they are essential for the future of the next generations. This work uses the inductive method and the bibliographic and documentary research procedure.

Keywords: Land Regularization. Sustainability. Environment.

\section{Introdução}

O problema deste artigo consiste na indagação sobre a possibilidade ou não do uso da legislação contemporânea sobre a Regularização Fundiária ser utilizada como um mecanismo de sustentabilidade urbana.

A Regularização Fundiária não era tratada no Brasil desde 2009, quando a Lei Federal $n^{\circ}$ 11.977/2009 apresentou-se como o primeiro marco jurídico de caráter nacional a dispor sobre a Regularização Fundiária, em áreas urbanas, de maneira abrangente.

De lá para cá, as cidades sofreram uma significativa modificação e ampliação, alterações significativas em relação às regras ambientais e urbanísticas, assim como à sustentabilidade, passaram a exigir uma medida urgente de combate às suas irregularidades. Daí, a importância do advento da Lei $n^{\circ} 13.465 / 2017$, conhecida como Lei de Regularização Fundiária Urbana (REURB). O referido diploma legal seria um conjunto de normas que abrangeriam medidas jurídicas, urbanísticas, ambientais e sociais, designadas a incorporar os núcleos urbanos informais, consolidados ou não, ao ordenamento territorial urbano, não importando se tais núcleos estivessem na área urbana ou rural, área pública ou privada.

Ao ponderar e aprofundar o conceito de cidade sustentável, no qual abrange uma série de direitos fundamentais da sociedade, destaca-se o direito à moradia, onde é possível identificar uma grande desigualdade entre as chamadas periferias e os centros urbanos, já que os mesmos não usufruem de tais direitos de forma igualitária. Estabelecer direito à moradia às populações menos favorecidas economicamente, utilizando a Regularização Fundiária é um instrumento para retirá-los da margem da lei.

A realidade das cidades brasileiras justificava a simplificação e alteração das normas de regularização fundiária dos imóveis que se encontram irregulares. A edição da Lei $13.465 / 2017$ traz a previsão para regularizá-10 .

Este trabalho tem como um dos objetivos conceituar e definir a regularização fundiária no ordenamento jurídico brasileiro como alternativa de atuação da Administração Pública na tentativa de diminuir a disparidade social. Propugna a organização do espaço urbano, por meio da inserção formal da população menos favorecida economicamente que ocupou tal espaço, originalmente, de modo irregular. Traz, ainda, a Lei 13.465/2017 e 
seus requisitos e, de forma sintetizada, apresenta os institutos da Regularização Fundiária e da Sustentabilidade Urbana.

A relevância do tema, justifica-se pelo crescimento desordenado dos grandes centros urbanos brasileiros em um curto espaço de tempo, percebendo-se que esse ocasionou diferentes problemas estruturais, tais como o desacordo da realidade fática ante a concretização do direito social à moradia e à dignidade humana, incluindo os direitos ao meio ambiente e à segurança pública.

As estimativas da UN-Habitat (2005, apud FORMAN, 2014, p. 4-5) mostram como se distribuirão as pessoas, mundialmente, em 2040: serão mais de 8,5 bilhões, dos quais $2 / 3$ estarão em áreas urbanas.

O presente artigo utiliza o método indutivo, através de uma pesquisa bibliográfica e documental.

\section{Conceito e definições de regularização fundiária no ordenamento jurídico brasileiro}

A Regularização Fundiária é um procedimento de modificação que tem por objetivo regularizar posse e/ou propriedade que se encontrarem ocupadas em áreas urbanas quais estejam em desacordo com a lei. A lei 13.465/2017 (REURB) foi criada de modo a garantir o direito social à moradia, à redução de distinções entre as classes sociais, à defesa do meio ambiente e por fim à função social da propriedade e da cidade. Segundo disposto no art. $9^{\circ}$, a lei estabelece medidas jurídicas, urbanísticas, ambientais e sociais destinadas à incorporação dos núcleos urbanos informais ao ordenamento territorial urbano e à titulação dos seus ocupantes. (MOURA, 2019).

Entretanto, para melhor compreensão da REURB precisa-se entender que a mesma não foi criada em 2017, pois em meados de
1980 já se tinha o "movimento nacional pela reforma urbana", e a partir de então a Constituição Federal de 1988, em seus artigos 182 e 183, trata do privilégio à função social da propriedade, à necessidade do Plano Diretor Municipal, entre outros mecanismos legais para a reforma urbana.

Seguindo esta evolução foi promulgado o Estatuto da Cidade de 2001 e a Medida Provisória 2.220, também de 2001, sendo que esta dispõe sobre a concessão de uso especial e cria o Conselho Nacional de Desenvolvimento Urbano. Posteriormente, ocorre a criação da Lei do SNHIS de 2005, que estabeleceu o Sistema Nacional de Habitação de Interesse Social, criando também o FNHIS e instituindo o Conselho Gestor do FNHIS. $\mathrm{Na}$ sequência, a legislação incorporou a Lei de Acesso aos Imóveis da União em 2007 e em 2009 foi promulgada a Lei que instituiu o Programa Minha Casa Minha Vida e legitimação de posse. Por fim, em 2017 ocorre a REURB, está regulada pela Lei 13.465/17. (ABELHA, 2017).

As medidas jurídicas correspondem de maneira especial à solução dos problemas com relação à posse, referindo-se aos casos em que o ocupante de uma área pública ou privada não possui um título que lhe proporcione garantia jurídica sobre sua ocupação. (MOURA, 2019).

As medidas urbanísticas dizem respeito às soluções para ajustar os parcelamentos à cidade regularizada, como a implantação de infraestrutura essencial, decorrentes dos loteamentos implantados sem atendimento das normas legais. A realocação das moradias em situação de perigo também entra nesse aspecto da possibilidade de regulamentação. (MOURA, 2019).

As medidas ambientais buscam solucionar o problema dos assentamentos implantados sem licenciamento ambiental e que não corresponde à legislação urbana e de proteção ao meio ambiente. (MOURA, 2019). 


\section{Competências constitucionais}

Percebe-se que fica ressaltada a competência da União em estabelecer normas gerais acerca da política urbana no art. 182 da $\mathrm{CF} / 88$ que, ao definir competência municipal, destaca a obrigação de fixação de diretrizes gerais por lei, aqui implícita como lei federal. (NASCIMENTO, 2013).

Além da competência de suplementar os Estados, o art. $25, \S 3^{\circ}$, da $\mathrm{CF} / 88$, prevê a possibilidade de instituições, como as da região metropolitana, para integrar o planejamento e execuções de funções públicas de interesse comum.

Tal dispositivo apresenta um conteúdo mais voltado para a competência material, mas o mesmo não deixa de envolver certa competência legislativa essencial a organização e ao planejamento das funções de interesse comum (NASCIMENTO, 2013)

Por fim, no que se refere aos municípios, a Constituição estabelece em seu art. 30, incisos I e VIII, que compete a eles: "[...] I legislar sobre assuntos de interesse local; [...] VIII - promover, no que couber, adequado ordenamento territorial, mediante planejamento e controle do uso, do parcelamento e da ocupação do solo urbano; [...]" (BRASIL, 1988)

Além deste artigo, encontra-se previsto no art. $182, \S 1^{\circ}$ que: “O Plano Diretor, aprovado pela Câmara Municipal, obrigatório para cidades com mais de vinte mil habitantes, é o instrumento básico da política de desenvolvimento e de expansão urbana". (BRASIL, 1988). Perceba-se que o Plano Diretor, aprovado pela Câmara Municipal, é a ferramenta básica da política urbana (NASCIMENTO, 2013)

$\mathrm{Na}$ esfera da formação de normas referentes ao desenvolvimento urbano, fica visível que a Constituição apresenta a necessidade de haver normas gerais aplicáveis ao país como um todo, mas também prevê a necessidade de normas de caráter mais específico que considerem as peculiaridades locais de cada município. (NASCIMENTO, 2013)

\section{Governança urbana sustentável}

A governança e a urbanidade encontraram na Constituição Federal de 1988 o valor da tutela dos direitos referentes à sociedade em conjunto com a preservação ambiental. É necessário proteger os direitos fundamentais do cidadão, mas para isso também deve ser observada a necessidade de uma governança sustentável para o benefício de toda a sociedade. (MACHADO; BODNAR; SILVA, 2017). Enfatiza-se a obrigação e a necessidade de a governança tentar harmonizar o desenvolvimento econômico com a proteção do meio ambiente. (BOSSELMANN, 2015, apud MACHADO; BODNAR; SILVA, 2017)

Percebe-se que a governança para a sustentabilidade é, fundamentalmente, diferente do conceito governança ambiental, considerada esta como "o primo pobre" da governança econômica. A governança para sustentabilidade traz consigo uma grande preocupação com o meio ambiente. É necessário pensar no ser humano da mesma forma que se pensa nos rios, florestas, cidades, entre outros.

O foco da governança atual é a comunidade humana. Todavia, para a sustentabilidade se faz importante a compreensão da vida de todos os seres do planeta, não somente dos seres humanos. A governança sustentável deve pensar além da vida e da existência humana (MACHADO; BODNAR; SILVA, 2017). Tem-se que o princípio da sustentabilidade como guia para projetos de lei e governança urbana trouxe um grande progresso, beneficiando, assim, toda a comunidade terrestre, valendo-se de que não estaria sendo beneficiado somente o ser humano, mas todo o 
ecossistema. (BOSSELMANN, 2015 apud MACHADO; BODNAR; SILVA, 2017) Observa-se, desta forma, que a preocupação com o acesso à moradia legal precisa ser analisada em conjunto com a sustentabilidade ambiental. As medidas sociais contemplam as soluções dadas à população beneficiária da REURB, de maneira especial nas ocupações por famílias de baixa renda, de forma a proporcionar o exercício digno do direito à moradia e à cidadania, gerando assim uma melhor qualidade de vida. (MOURA, 2019).

Em março de 2017, o governo publicou o Decreto $\mathrm{n}^{\mathrm{o}}$ 9.310, que institui as normas gerais e os procedimentos aplicáveis à Regularização Fundiária Urbana, regulando o disposto pela lei $n^{\circ} 13.465$. Essa lei ramifica a Regularização Fundiária em três espécies, sendo elas de interesses sociais (REURB-S) e específicos (REURB-E), assim como inominada (REURB-I). (COSTA, 2018).

A Regularização Fundiária de Interesse Social (REURB-S) é aplicável aos núcleos urbanos informais ocupados predominantemente por população de baixa renda, assim afirmado em ato do Poder Executivo Municipal. As áreas objetos podem ser definidas por meio da ZEIS ${ }^{1}$, quando, em regra, são estabelecidas no Plano Diretor Urbano de cada município. Porém, essas áreas também podem ser definidas por meio de um ato do Poder Público, como por exemplo, um decreto. Essa exceção se faz presente, principalmente, em pequenos municípios que não possuem a obrigatoriedade de criação do Plano Diretor Urbano pelo estatuto das cidades (Art. 41, I, da Lei 10.257/2001).

Cada espécie da REURB tem órgãos responsáveis com suas funções específicas a serem seguidas. Na REURB-S cabe ao poder público, diretamente, e à administração pública, indiretamente, a implementação da infraestrutura essencial, como as melhorias habitacionais que estão previstas nos projetos de regularização, equipamentos comunitá- rios, assim como o dever de arcar com sua manutenção (BRASIL, 2017).

Na REURB-S nos casos em que os núcleos urbanos informais ocuparem a área de preservação permanente (APP), está disposto que somente será acolhida a Regularização Fundiária por meio de aceitação do projeto de regularização fundiária no formato da Lei $n^{\circ} 13.465 / 2017$. O projeto da REURB-S compreende estudo técnico que evidencie a melhoria das condições ambientais em relação à ocasião anterior à adoção das medidas nele recomendado. A REURB-S observa o disposto no art. 64 da lei 12.651/2012 (BRASIL, 2012).

A Regularização Fundiária de Interesse Específico (REURB-E) é aplicável aos núcleos urbanos informais ocupados pela população não contemplada na REURB-S. São os núcleos urbanos informais, os quais estão sendo ocupados por pessoas com uma qualidade de vida melhor do que a encontrada na população que a REURB-S contempla, mas que ainda não têm uma habitação juridicamente regularizada, não têm documento de seu domínio. Mas ressalta-se que dentro dos núcleos que a REURB-E contempla, pode, sim, haver habitações ocupadas por moradores de baixa renda, da mesma forma que se pode encontrar na REURB-S moradores que não são de baixa renda, mas que serão favorecidos.

Na REURB-E, conforme o art. 38 cabe ao Distrito Federal e aos Municípios, determinar, por ocasião da aprovação dos projetos de Regularização Fundiária, nos limites da legislação de regência (BRASIL, 2017).

Na REURB-E, os núcleos urbanos sem formalidades, que ocupam as APPs não identifica como área de risco, somente serão admitidas por meio de aprovação do projeto da Regularização Fundiária Urbana. (BRASIL, 2017)

Segundo oArt. $13, \S 2^{\circ}$, da Lei 13.465/2017, os atos referentes às duas espécies de REURB 
independem da comprovação do pagamento de tributos ou penalidades tributárias. A cobrança da quitação de tributos municipais, para se obter a regularização do seu imóvel, passa a ser vedada pela lei do REURB.

Na REURB-I, para imóveis anteriores a 19 de dezembro de 1979, não será necessário apresentar estudos técnicos. O estudo técnico passa a ser de responsabilidade do próprio município no momento que este tiver órgão legalmente habilitado; quando não houver a atribuição é competência do Estado.

Para se falar da história do acesso à moradia, pode-se iniciar partindo de um marco, o ano de 1850, quando a Lei de Terras nasce como instrumento que visa a estabelecer critérios para aquisição de propriedade no Brasil, fulcro na lição de Arlete Moisés Rodrigues (1990):

Com a Lei 601 de setembro de 1850, conhecida como lei das Terras só quem podia pagar era reconhecido como proprietário juridicamente definido lei. Além do valor moral, a propriedade como ocorria anteriormente há também valor econômico e social. O capitalismo se desenvolveu e impôs politicamente o reconhecimento da propriedade privada da terra (RODRIGUES, 1990, p.17).

Após esta era, a busca massiva pelo direito à moradia se aguça com a abolição da escravatura, pois, até então, a inquietação com moradia não era algo primordial, pois a maior parte da população era constituída de escravos que viviam junto a seu soberano, segundo Lehfeld (1988):

Com a libertação dos trabalhadores escravizados - oficializada pela Lei Áurea, de 1888 - e, ao mesmo tempo, com o impedimento de os mesmos se transformarem em camponeses, quase dois milhões de adultos ex-escravos saem das fazendas, das senzalas, abandonando o trabalho agrícola, e se dirigem para as cidades, em busca de alguma alternativa de sobrevivência, agora vendendo "livremente" sua força de trabalho. Como ex-escravos, pobres, literalmente despossuídos de qualquer bem, resta-lhes a única alternativa de buscar sua sobrevivência nas cidades portuárias, onde pelo menos havia trabalho que exigia apenas força física: carregar e descarregar navios. E, pela mesma lei de terras, eles foram impedidos de se apossarem de terrenos e, assim, de construírem suas moradias: os melhores terrenos nas cidades já eram propriedade privada dos capitalistas, dos comerciantes etc. Esses trabalhadores negros foram, então, à busca do resto, dos piores terrenos, nas regiões íngremes, nos morros, ou nos manguezais, que não interessavam ao capitalista. Assim, tiveram início as favelas. A lei de terras é também a "mãe" das favelas nas cidades brasileiras (LEHFELD, 1988, p. 7).

Sendo assim, existiam pessoas que não possuíam o valor aquisitivo suficiente para contrair uma pequena porção de terra e, desta forma passavam a buscar outras opções de moradia, que na maioria das vezes eram irregulares (MOURA, 2019).

A cidade contemporânea começou a ganhar contornos claros após o advento da Revolução Industrial. Esse processo de mudança do perfil de distribuição da população desenvolveu-se muito rapidamente, trazendo vários problemas de ocupação do solo urbano. Em pouco mais de 200 anos, as cidades cresceram e se modificaram mais que em qualquer outro período da história (MIGUEZ; VERÓL; REZENDE 2015).

\section{A Lei $N^{0} 13.465 / 2017$ e seus requisitos legais}

A lei que trata da Regularização Fundiária teve como requisito legal instituir mecanis- 
mos para aprimorar a eficiência dos procedimentos de alienação de imóveis da união, alterar algumas leis, medidas provisórias e decretos.

A lei 13.465/2017 passa, assim, a dispor sobre a regularização fundiária rural e urbana, apresentando seus legitimados instrumentos e o procedimento para cada situação da REURB.

Conforme o art. 14 da Lei 13.465/17, entre os principais legitimados para a execução da REURB estão os Municípios e o Distrito Federal (BRASIL, 2017).

A demarcação urbanística é um procedimento administrativo, proposto pelo poder público, no âmbito da regularização fundiária de interesse social, para identificar os imóveis públicos e privados que estão sendo compreendidos pelo núcleo urbano informal, definindo, assim, os seus limites, localização e confrontante e a sua área, buscando, dessa forma, por finalidade reconhecer os seus ocupantes e classificar a natureza e o tempo das suas respetivas posses (MOURA, 2019)

É no momento da elaboração do projeto de Demarcação que os interessados passam a ter ciência das ações necessárias à legalização. Finalizando o projeto, este com a descrição exata de medidas e confrontantes, este é aprovado pelo órgão responsável do município promotor ou interveniente e, em seguida, se emite o Auto de Demarcação Urbanística. Neste momento o município notifica a união e o estado quanto à existência da referida demarcação para que se houver alguma impugnação os mesmos se manifestem em 30 dias. Também se deve notificar os confrontantes da área demarcada e os demais interessados, estes então por meio de edital, para que, querendo, manifestem-se no prazo de 15 dias. Não havendo nada de impedimentos o projeto é prenotado no Cartório de Registro de Imóveis (CRI), junto dos resultados das notificações dos entes. (CILENTO, 2017)
A legitimação de posse é um ato do poder público, sendo que a mesma tinha sua aplicação regulamentada pela lei $n^{0}$ 11.977/09 e, agora, ganha novos aspectos com a lei $\mathrm{n}^{\mathrm{o}}$ 13.465/17. A legitimação de posse só pode ser aplicada em áreas privadas, conforme regulamenta o art. $25 \S 2^{\circ}$ da lei $13.465 / 17$, podendo ser transferida por causa mortis ou inter vivos. A legitimação de posse pode ser convertida em propriedade, depois de decorrido o prazo de 5 (cinco) anos, sem ter a necessidade de pratica registral, desde que sejam atendidos os requisitos do art. $26 \S 2^{\circ}$ da lei 13.465/17. (BRASIL, 2017)

Segundo Paiva (2017), a legitimação fundiária pode ser considerada o instituto mais importante e eficaz da Regularização Fundiária. É procedimento de reconhecimento da aquisição originária do direito real de propriedade sobre a unidade imobiliária objeto da REURB, conferido por ato do poder público.

Para um bom andamento do Processo Administrativo de Regularização Fundiária, este deverá obedecer a determinadas etapas estas dependendo da modalidade de regularização diligenciada, e nos termos descritos na Lei ${ }^{\circ}$ 13.465/17 e no Decreto $n^{\circ}$ 9.310/18.

A REURB-S versa sobre a Regularização Fundiária aplicável aos núcleos urbanos informais, ocupados especialmente pela população de baixa renda e a REURB-E versa sobre os demais casos. O critério utilizado para estes casos, aplicável aos núcleos urbanos informais, ocupados, predominantemente $(50 \%+1)$, por população de baixa renda, assim declarados em ato do Poder Executivo municipal, não impediria, que famílias com condições econômicas mais elevadas ocupem imóveis naquele núcleo (MOURA, 2019).

Nas duas formas da REURB sendo ela de Interesse Social ou Interesse Específico, poderá ser admitido o uso misto de atividades como uma forma de promover a geração de 
emprego e renda e, desta forma, também a integração social naquele núcleo urbano informal, conforme prevê o art. 13, §4 da Lei $n^{\circ}$ 13.465/1. (MOURA, 2019)

O processamento, encontra-se descrito no inciso II, do art. 28, estabelece que instaurada a REURB, fica a encargo do município proceder as buscas necessárias para que seja determinada a titularidade do domínio dos imóveis onde se encontra o núcleo urbano informal. Todo o procedimento administrativo e suas etapas estão estabelecidos no art. 31, da lei de REURB. (BRASIL, 2017)

\section{Regularização fundiária urbana e a sustentabilidade urbana: os mecanismos jurídicos existentes}

Ao se tratar dos mecanismos jurídicos dispostos na lei de Regularização Fundiária, logo no início, a Lei 13.465/17 traz em seu art. $9^{\circ}, \S 1^{\circ}$, que o poder público deve observar os princípios da sustentabilidade econômica, social e ambiental. (BRASIL, 2017)

Em seguida, encontra-se respaldo jurídico no Decreto 9.310/2018, em seu art. $4 \S 5, \mathrm{~V}$ e no $\S 6$, IX, onde todos visam a tratar a sustentabilidade urbana, sendo ela na maioria ambiental (BRASIL, 2018).

A lei apresenta em seu texto a sustentabilidade como um dos princípios a se analisar para a realização efetiva da REURB, sendo que se faz necessário comprovar a melhoria das condições de sustentabilidade urbano-ambiental também.

Para um melhor entendimento da cidade sustentável, faz-se necessário analisar o estatuto da cidade Lei $\mathrm{n}^{\circ} 10.257 / 2001$ Nele é tratada à garantia do direito a cidades sustentáveis, regulamentado pelo art. $2^{\circ}$ (BRASIL, 2001).

O termo sustentabilidade foi construído no ano de 1984, a partir da Comissão do Meio
Ambiente e Desenvolvimento. Para muitos a sustentabilidade é vista como um termo que indica os impactos e questões ambientais, mas ao pensar nela como um modo de vida, passa-se a ter um significado maior que abrange outras questões, como mudança de comportamento, não somente da população. Sendo assim, faz-se necessária a criação de novos planos para uma qualidade de vida da humanidade.

$\mathrm{Na}$ atualidade, está cada vez mais presente o conceito de sustentabilidade, presente também em conferências que tratam do tema. Tudo isso porque as atuais metrópoles enfrentam diversos problemas como a poluição dos centros urbanos, desigualdades sociais, etc.

O Estatuto da Cidade elenca instrumentos como o Plano Diretor e traz também o desenvolvimento sustentável ao meio urbano, por meio da afirmação do direito às cidades sustentáveis. (BRASIL, 2001).

A regularização fundiária é uma ferramenta que possibilita a dignidade dos moradores que por vezes foram forçados a adquirir terrenos em situações de risco, muitos por não possuírem condições financeiras se sujeitam a adquirir estes imóveis para não ficar sem moradia, mas por muitas vezes passam a viver em um local com péssimas condições e pouca infraestrutura. $\mathrm{O}$ estado, em muitos casos, se omitiu e permitiu que a situação chegasse a um estado péssimo, com pouco ou, por vezes, sem infraestrutura urbana e sem qualidade de vida. (MACHADO; BODNAR; SILVA, 2017)

Um dos principais desafios para que tornar as cidades sustentáveis é a falta do acesso da população de baixa renda a moradias regularizadas e com infraestrutura. Desta forma também se necessita de um melhor planejamento urbano este adequado a realidade de cada município. São necessárias melhorias adaptadas a cada município, uma vez que o Plano Diretor só se faz obrigatório em municípios com mais de 20 mil habitantes. 
O que se busca não é diminuir o desenvolvimento sustentável a fim de beneficiar a sustentabilidade, pois desta forma se estariam diminuindo os empregos e novamente incentivando a pobreza o que se busca é o balanceamento entre a economia e a sustentabilidade.

Beck pontua que mesmo que pareça impossível solucionar algum problema, devemos tomar alguma atitude frente a ele. Não basta manter uma distância crítica desta crise civilizatória geradora de riscos com escárnios, cinismos e indiferenças só porque parece que o fim é inevitável, ainda que de forma minoritária devemos fomentar alguma ideia, estabelecer parâmetros, propor soluções, ainda que aparentem serem utópicas, a terra é o nosso lar (BECK, 2011, p.49 apud MACHADO; BODNAR; SILVA, 2017, p.144).

Mesmo que se encontrem desafios e que estes pareçam intransponíveis e de difícil solução, sempre é necessário ter-se iniciativa, já que a sustentabilidade urbana em conjunto com o acesso à moradia legal é uma das formas para uma vida digna.

Com a Constituição de 1988 os municípios foram instituídos como entidade federativa, ou seja, com direito de plena autonomia, auto-organização e autoadministração. Desta forma é dever do município "promover, no que couber, o adequado ordenamento territorial, mediante planejamento e controle de uso, do parcelamento e da ocupação do solo urbano" (art.30, inciso VIII, CF/88) (SILVA, 2014).

Fica indispensável que haja uma atuação em conjunto do poder executivo, legislativo e judiciário para a concretização dos programas de Regularização Fundiária.

A Constituição Federal é clara em garantir papel relevante ao município na proteção e no desenvolvimento urbano, aqui se inclui os programas de Regularização Fundiária, em diversos dispositivos da lei encontra-se a imposição da atuação do município, por exemplo na aprovação do projeto, no licenciamento urbanístico e ambiental. Cabe ao município também conciliar a REURB em conjunto com a sustentabilidade, sendo assim necessária uma complexa avaliação dos acessos à moradia dos seus munícipes. (SILVA, 2014)

O ente federado mais próximo dos cidadãos é o município. Sendo assim, as pessoas ali constroem suas moradias, trabalham e vivem na cidade, cabendo ao Município a obrigatoriedade e o papel fundamental para atuar nesta problemática que é a do cidadão ter acesso à moradia de forma legal.

As ações que têm em vista à efetividade da Regularização Fundiária Urbana Sustentável precisam, inicialmente, estar inseridas no Plano Diretor. Tratando-se do termo sustentável, faz-se necessário que se tenha o trabalho em conjunto com as ações voltadas à efetivação da segurança jurídica da posse, em conjunto com determinadas obras de urbanificação.

A Regularização Fundiária não pode ser vista como uma solução das graves distorções urbanísticas, ambientais e sociais Ela será um processo conciliador com inúmeros programas habitacionais, estes voltados para os mais necessitados. Aplicar de forma correta os instrumentos da política urbana, neste caso a Regularização Fundiária, sugere uma ação do poder público em favor da população de baixa renda. Estas pessoas que pelo fato de serem de classe mais desfavorecida, economicamente falando, são impulsionadas a residirem em locais inapropriados por falta de opções de moradia. (MUKAI, 2007)

A Regularização Fundiária Urbana Sustentável só será efetiva quando trabalhada de forma integrada, colocando os direitos em conjunto com a questão ambiental e social. Esta regularização sustentável é um passo na integração da cidade real com a cidade legal, 
sendo que isso somente se efetivará quando utilizados todos os meios e instrumentos necessários para sua realização (MUKAI, 2007).

A efetivação só será possível quando trabalhada de forma conjunta entre o meio ambiente e a garantia do pleno exercício do direito à moradia e uma estrutura urbana. Isso tudo pensando sempre nas futuras gerações, para que assim seja possível uma efetiva Regularização Fundiária Urbana Sustentável.

\section{Conclusão}

No decorrer deste artigo, possibilitou-se uma análise da sustentabilidade urbana por meio da regularização fundiária Foi identificado que a população de baixa renda é excluída do contexto urbano. Por não haver políticas públicas efetivas, o direito à moradia continua a ser dificultado. Desta forma, implementações da Regularização Fundiária ficam impedidas de serem colocadas em prática.

Observou-se quão efetiva é a Regularização Fundiária no que concerne ao direito à moradia isto se a mesma for colocada em prática.

A Regularização Fundiária dos assentamentos informais é decorrente do direito à moradia, favorecendo assim a ideia da concretização da Regularização no local em que se encontram as irregularidades. É evidente que, onde, por motivos de natureza ambiental, não for possível cumprir a pretendida regularização, impõe-se que ao Poder Público cabe o dever de buscar alternativas para que os cidadãos do assentamento informal não tenham o seu direito constitucional reconhecido, negado.

A utilização do conceito de sustentabilidade não agrega somente as considerações de natureza ambiental, mas o alcance de direitos, estes ligados ao desenvolvimento das funções sociais da cidade e, estas, dispostas no Estatuto da Cidade.

Ao reconhecer os direitos fundamentais dos cidadãos, se efetiva o conceito de cidade sustentável, visto que o mesmo abrange toda a coletividade. Ao cidadão cabe exercer sua condição de cidadão e participar, efetivamente, na busca dos seus direitos, para assim, se obter uma cidade sustentável.

Para garantir a efetividade da Regularização Fundiária Sustentável, as ações que buscam essa concretização precisam estar no Plano Diretor de cada cidade. A busca pela realização da mesma será um passo para integrar a cidade real com a cidade legal. A efetivação da REURB só vai ter êxito se trabalhada em conjunto com o meio ambiente e a garantia do direito à moradia e uma efetiva estrutura urbana, pois assim, poder-se-á garantir que as futuras gerações desfrutem de uma Regularização Fundiária Urbana Sustentável.

\section{NOTAS}

${ }^{1}$ As Zonas Especiais de Interesse Social são porções do território destinadas, predominantemente, à moradia digna para a população da baixa renda por intermédio de melhorias urbanísticas, recuperação ambiental e Regularização Fundiária de assentamentos precários e irregulares. 


\section{REFERÊNCIAS}

ABELHA, A. Lei 13.465/17 (Parte VI): desmistificando a Reurb. 2017 Disponível em: https://www. migalhas.com.br/depeso/264717/lei-13465-17-parte-vi-desmistificando- a-reurb. Acesso em: 24 mar. 2020 .

BRASIL. Decreto $\mathbf{n}^{\mathbf{0}}$ 9.310, de 15 de março de 2018. Institui as normas gerais e os procedimentos aplicáveis à Regularização Fundiária Urbana e estabelece os procedimentos para a avaliação e a alienação dos imóveis da União. Disponível em: http://www.planalto.gov.br/ccivil_03/_ato20152018/2018/Decreto/D9310.htm Acesso em: 15 jun. 2021.

BRASIL. Lei n' 10.257, de 10 de julho de 2001. Regulamenta os arts. 182 e 183 da Constituição Federal, estabelece diretrizes gerais da política urbana e dá outras providências. Disponível em: http://www.planalto.gov.br/ccivil_03/leis/leis_2001/110257.htm. Acesso em: 11 set. 2019.

BRASIL. Lei no 12.651, de 25 de maio de 2012. Dispõe sobre a proteção da vegetação nativa. Disponível em: http://www.planalto.gov.br/ccivil_03/_Ato2011-2014/2012/Lei/L12651.htm. Acesso em: 11 set. 2019.

BRASIL. Lei $\mathbf{n}^{\mathbf{0}} \mathbf{1 3 . 4 6 5}$, de 11 de julho de 2017. Dispõe sobre a regularização fundiária rural e urbana, sobre a liquidação de créditos concedidos aos assentados da reforma agrária e sobre a regularização fundiária no âmbito da Amazônia Legal. Disponível em: http://www.planalto.gov.br/ ccivil_03/_Ato2015-2018/2017/Lei/L13465.htm. Acesso em: 11 set. 2019.

CILENTO, B. P. Demarcação urbanística e legitimação de posse na regularização fundiária de interesse social: aplicação no assentamento São Bento do Recreio (Valinhos/SP). Dissertação (mestrado) - Pontifícia Universidade Católica de Campinas, Centro de Ciências exatas, Ambientais e de Tecnologias, Pós-Graduação em Urbanismo, 2017. Disponível em: http://tede.bibliotecadigital. puc-campinas.edu.br:8080/jspui/handle/tede/1066 Acesso: 15 jun. 2021.

COSTA, N. Regularização fundiária urbana: afinal, o que é e por que fazer? 21 de maio de 2018. Disponível em: http://geoeduc.com/blog/regularizacao-fundiaria-urbana/. Acesso em: 11 set. 2019.

FORMAN, R. T.T. Urban ecology. Science ofCities. Cambridge, UK: Cambridge University Press, c. 2014.

LEHFELD, N. A. S. Uma abordagem populacional para um problema estrutural: a habitação. Petrópolis: Vozes, 1988. Disponível em: http://www.sst.sc.gov.br/arquivos/id submenu/230/publiicacao_planhab_capa.pdf. Acesso em: 02 jun. 2019.

MACHADO, M. F.; BODNAR, Z.; SILVA, K. C. Governança para a sustentabilidade urbana e a regularização fundiária. Revista da ESMESC, v.24, n.30, p. 329-350, 2017, DOI: http://dx.doi. org/10.14295/revistadaesmesc.v24i30.p329. Disponível em: https://revista.esmesc.org.br/re/article/ view/173/146 Acesso em: 25 jun. 2021.

MIGUEZ, M. G.; VERÓL, A. P.; REZENDE, O. M. Drenagem urbana: do projeto tradicional à sustentabilidade 1. ed. - Rio de Janeiro: Elsevier, 2015.

MOURA, J. A. Cartilha - Regularização fundiária urbana: Aspectos Práticos Da Lei 13.465/2017. Disponível em: https://www.sinoreg-es.org.br/_Documentos/Upload_Conteudo/arquivos/CARTILHA_ REGULARIZACAO_FUNDIARIA_URBANA_2017.pdf. Acesso em: 11 set. 2019.

MUKAI, S. T. Regularização fundiária sustentável urbana e seus instrumentos. Dissertação (Mestrado) - Pontifícia Universidade Católica de São Paulo PUC-SP. 2007 
NASCIMENTO, M.C.G. Regularização fundiária urbana de interesse social no direito brasileiro. 2013. Dissertação (Mestrado em Direito) - Faculdade de Direito da Universidade de São Paulo, 2013. Disponível em: https://edisciplinas.usp.br/pluginfile.php/4108502/mod_resource/content/1/ Dissertacao_Final_Mariana_Chiesa_Gouveia_Nascimento\%20\%283\%29.pdf. Acesso em: 11 set. 2019.

PAIVA, J. P. L. Regularização fundiária: impactos e aspectos relacionados ao desenvolvimento das cidades e ao direito de moradia de acordo com a Lei n. 13.465/17. 2017. Disponível em: http:// registrodeimoveis1zona.com.br/wpcontent/uploads/2017/09/Regulariza\%C3\%A7\%C3\%A3oFundi\%C3\%A1ria-TOTAL.pdf. Acesso em: 30 mar. 2020.

RODRIGUES, A. M. Moradia nas cidades brasileiras. 3. ed. São Paulo: Contexto, 1990. Disponível em: https://scholar.google.com.br/citations?user=JAVpyvsAAAAJ\&hl=pt-BR Acesso em: 15 jun. 2021

SILVA, L. D. O. Regularização fundiária de interesse social: instrumentos em favor do município. Conteúdo Jurídico. Brasília-DF. Disponível em:https://conteudojuridico.com.br/consulta/ Artigos/40252/regularizacao-fundiaria-de-interesse-social-instrumentos-em-favor-do-municipio. Acesso em: 21 abr. 2020. 